
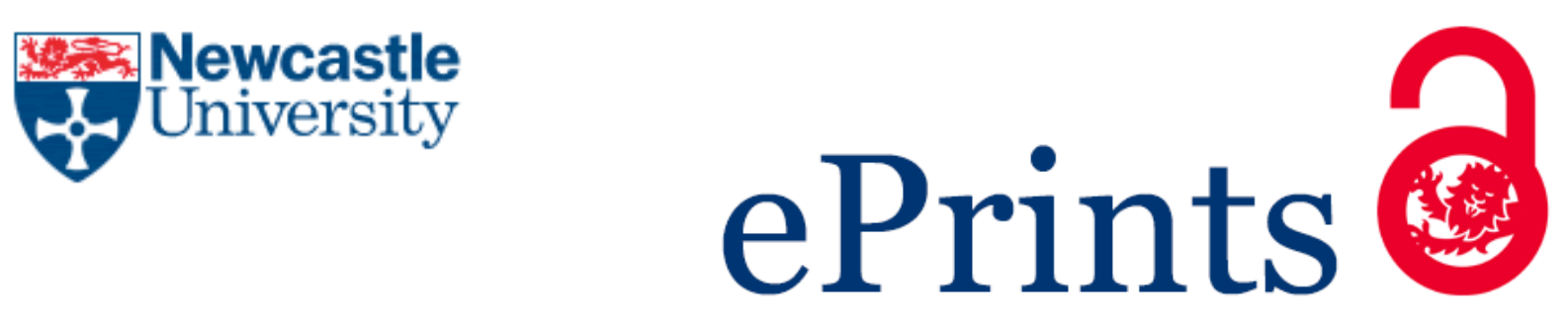

Gilroy R, Brooks L. (2016)

Fair shares for all: The challenge of demographic change.

In: Davoudi, S; Bell, D, ed. Justice and Fairness in the City: A Multi-Disciplinary Approach to 'Ordinary' Cities.

Bristol: Policy Press, pp.213-230.

\title{
Copyright:
}

This is a post-peer-review, pre-copy edited version of a chapter published in Justice and Fairness in the City: A Multi-Disciplinary Approach to 'Ordinary' Cities. Details of the definitive published version and how to purchase it are available online at: https://policypress.co.uk/justice-and-fairness-in-the-city

Date deposited:

$07 / 12 / 2016$

Embargo release date:

27 April 2018 
31 While all socially constructed categories are in flux, the concept of 32 'old age', our understanding of what it is to be an older person, is 33 now being contested and redefined (Hockey et al, 2013). In part, this 34 is due to the greater number and proportion of people over 50 in 35 global populations and the reasonable expectation that more people 36 can anticipate living into their eighth decade or beyond. This in turn 37 leads to a new landscape of later life that emerges as a multigenerational, 38 highly differentiated experience that is impossible to encapsulate in 39 traditional images. This has caused some commentators (for example, 40 Clapham, 2014) to question whether age as a social category has any 41 validity, though it is clearly still in common usage to determine access 42

\section{Fair shares for all: the challenge of demographic change}

\author{
Rose Gilroy and Elizabeth Brooks
}

\section{Introduction}

This chapter focuses on older people's experience of social injustice, discussed here as oppression. We begin with a discussion of how 'old age' as a social category is being reconstructed before turning to consider the utility of oppression as a lens to explore the experiences of older people. Using the framework developed by Young (1990) this chapter considers the operation of exploitation, marginalisation, violence, powerlessness and cultural imperialism, drawing on national and local sources of evidence but more significantly on the narratives of older people living mainly in Newcastle. The discussion concludes by considering the work of Newcastle City Council and its partners in striving to make a reality of their age-friendly city commitment. To what extent do these partnership programmes create transformation or the possibility of transformative action?

\section{Rethinking old age}




\section{1}

to a range of services and environments, which in themselves may be constructed in response to particular definitions of older age.

In response to the broad span of later life that might be some 50 years, new subcategories of 'old age' have emerged, with the most prevalent being the idea of the baby boomer. Much has been written on this cohort - in particular what might be more correctly termed the 'first wave' baby boomers born in the period after the Second World War - that has captured the public imagination with its, supposed, defining characteristics of individual choice making, prosperity, ownership and greater opportunities in the post work phase of life for self-actualisation. It is these characteristics that are associated with the concept of the 'third age'. Against this background new agendas have emerged. The 'successful ageing' agenda attempts to reframe later life as a time of possibilities in which individuals might make a continued, but different, contribution to society (Rowe and Kahn, 1997). This is a welcome development; however, 'the debate serves as a convenient shelter for a wide range of policy discourses and initiatives' (Walker, 2004: 75). In its guise as 'productive ageing', the vision has often been narrowed to the demand for deferred retirement (Higgs and Jones, 2009). As 'active ageing', it has been recast as a discussion of health and positive lifestyle choices. As Higgs et al (2009: 690) comment, this discourse has come to 'overwhelm our understanding of later life', as health is seen as not only central to any construct of a successful old age but increasingly a 'required goal' for individuals. In the current time of public finance constraint, it is expedient for neoliberal governments to promote the importance of individual responsibility (Means and Evans, 2014) and to set this within a discourse of ageing as a dire economic problem - the 'age quake' that threatens to further destabilise languishing economies.

If the idea of later life as a period of inevitable and progressive decline is firmly rejected by the baby boomers then a new construction of the 'fourth age' - sometimes termed the 'oldest old' - has emerged to encapsulate the onset of frailty that might encompass disability, bereavement, loneliness, incontinence and cognitive decline. It is as if we have created a 'scary room' into which we have pushed all those aspects of later age that may affect us and firmly bolted the door on this: for if successful ageing is about health and vitality then a decline into disability and frailty can too easily be seen as a personal failure. The fourth age has become in many ways the 'new old age' signalled not by chronology but by physical and social transitions. It is, however, important to note that as the baby boomers have transformed thinking about early stage post work life, it is anticipated they may challenge 
1 these fourth age concepts as they age into their ninth and tenth decades 2 and beyond.

3 If the concept of later life is in flux and its language still emerging, the 4 context of ageing has also changed. As the world becomes increasingly 5 urbanised, so ageing becomes an increasingly urban experience. This 6 has led to the World Health Organization's (WHO) Age-friendly Cities 7 programme that established a worldwide network of cities committed 8 to making physical changes in the urban fabric and improving the 9 daily life experience of older citizens, not with a mission to serve any 10 'special needs', but rather to pay attention to older people as a matter 11 of social justice:

12

It should be normal in an age-friendly city for the natural and built environment to anticipate users with different capacities instead of designing for the mythical 'average' (ie young) person. An age-friendly city emphasises enablement rather than disablement; it is friendly for all ages and not just 'elder-friendly' (WHO, 2007: 72).

The challenge is not just to 'add in' older people, but by their inclusion to transform the urban experience challenging not only those policy and societal practices that shape the physical fabric but all that restrict the lives of older people.

\section{Turning to the framework of oppression}

In exploring the experience of injustice in the lives of older people, Iris Marion Young's (1990) framework of oppression rejects simple explanations that suggest that a redistribution of material goods is the complete solution to inequality, but rather confronts the myriad ways in which power is exercised in society. In the UK there has been positive action to improve the incomes of older people through pushing back retirement and improving pensions; however, these benefits are unevenly experienced. Beyond matters of income and wealth, in the context of the UK and its shrinking welfare state, oppression can be uncovered in the 'everyday practices of a well intentioned liberal society' (Young, 1990: 41) and in the way cuts are made in publicly provided or procured services that may signal whose lives are valued and whose are not. Oppression is seen as [rooted in] 'unconscious assumptions and reactions of well meaning people in ordinary interactions, media and cultural stereotypes, and structural features of bureaucratic hierarchies and market mechanisms - in short, the normal processes of everyday 


\section{1}

life' (Young, 1990:41). The analysis that follows uses Young's five faces of oppression: exploitation, marginalisation, violence, powerlessness and cultural imperialism as ways of understanding the narratives of older people. The fieldwork was commissioned by Joseph Rowntree Foundation in June 2009 with the intention of looking at quality of life from older people's perspectives (Gilroy, 2009). Within an eight-week timescale, the research drew in the newly retired to those in their 90s and the terminally ill; the affluent and those on low incomes; those in a range of home settings including specialist housing and care homes; and from a diversity of faith and mother tongues. Where feasible, focus groups were held that drew together people with a common bond, often locality based. A total of 54 people took part in seven focus groups, including two where interpreters were used. A further 13 interviews were undertaken to explore some issues in greater depth and to include those seldom heard, including Jewish elders and frail housebound people. To preserve anonymity, all participants are referred to by assigned, rather than their actual, names.

\section{Exploitation}

From a Marxist perspective, worker exploitation occurs when the labour of one group is controlled by and benefits others. In the context of older people, their exploitation could be seen as taking the form of substantial unpaid care work to sustain parents, spouse, adult family, friends and children. Clearly the state benefits from this economy of love and the savings to the public purse are very great. As carers of adults, older people provide an informal economic contribution of $£ 11.4$ billion in addition to the $£ 6.6$ billion of child care that they provide that enables their adult children to work and pay taxes. All this is in addition to the $\mathcal{E}^{5}$.8 billion of volunteering that older people give in a multitude of welfare, cultural, education and social arenas (Carers UK, 2014).

Closer to home in Newcastle, half of all unpaid care is given by those aged $50(+)$ and one third of those providing 50 hours or more of unpaid care per week is over 65 years of age (NCC, 2013). The personal cost to these carers in health terms may be severe. It is also evident that, for those who are mature workers, there may be financial penalties to be borne that impact on their own choice-making abilities in retirement. 'The peak age for caring is $45-65$, resulting from the highest likelihood of needing to care for an older parent, meaning that the most intense pressure often comes at the peak of carers' careers 
1 when the loss of employment can become irreversible' (Carers UK, 2014: 45).

3 None of the participants in the fieldwork were providing child care, 4 none were carers for parents, though one recent retiree had moved 5 back into the locality with a view to looking after his parents-in-law 6 in the near future. Only two were carers for their spouse, though 7 several were now alone after years of care giving. How individuals 8 view their caring responsibilities is clearly highly individualised. One 9 woman spoke of her sick husband as a burden who took all her time 10 and energy, while Mr Francis revealed the emotional cost to himself 11 as he saw his wife become frailer and less able to engage:

12

13 Interviewer:

14

15

16 Mr Francis:

17

18

19

20

21

22

23

24

25

26

27

28

29

30

31

32

33

34

35

36

37

38

39

40

41

42
'The last thing I wanted to ask you was if you could change one thing that might improve your quality of life what might that be?'

'I think it would be my wife not being blind and disabled because in so many ways this is a constraint, it's not just you don't do things it's that you haven't got an active partner, so for my part not so much my own health. The contact between us has really been very important and the fact that this has broken down in the last years since her health and sight have gone and the limitation that is imposed. It's really going back to social contact, rich social contact is the thingeven me, and I would have said I am not a very social person, I got my social contact within ... there is a lot of shared values with my wife, a profound bond right the way through, a core of shared concerns really.'

Care giving to a spouse is bound up with a sense of reciprocity and responsibility; for some it is part of the marriage vows of being with that person 'through sickness and in health'. For some it is a duty borne under sufferance; for others it is simply about love. In the context of older people, to talk of their unwaged care work as exploitation is consonant with Young's analytical framework but on a personal level may feel deeply wrong. This is, of course, the wicked issue in that love makes us complicit in our own exploitation. How does a just society better incorporate families into care systems without taking advantage of them? How does society support what might be a powerful shared experience (Horwitz, 2014)? More broadly, what does it say about our current view of later life that unsupported heavy duty care by older people is so prevalent as to seem unremarkable? 


\section{Marginalisation: a multifaceted picture}

\section{Poverty of resources}

Marginalisation in a capitalist society, where income is frequently the key to a greater range of options can be interpreted as lacking the financial competence to make choices and to feel part of the mainstream. A political commitment to raise pensioner households out of poverty has resulted in the average older person's household now having an income of $f^{24,804}$ - just short of the average (individual) salary at $\mathcal{L}^{26,500}$ (IFS, 2013). Much of this increase can be attributed to greater engagement in the labour market by those over 60 due to changes in the state retirement age for men, and, particularly, for women. The spread of better occupational pensions has benefited the income of those under 75 but for older cohorts these schemes were largely unavailable, creating marked income differences (DWP, 2014). In the fieldwork this was reflected in the narratives of recent retirees, who were among the best off as outright homeowners, car drivers and with enough disposable income to pursue a range of activities. In spite of increases in older people's average incomes, 14\% of pensioner households still live in poverty, measured as having 60\% or less of median income after housing costs. Living on a low income is not confined to people in later life of course but as Ginn asserts, 'pensioners differ from the working age population in having no opportunity to increase their income in future: those who are poor remain so' (2010: 51).

The positioning of households on the spectrum of those with enough income to make choices is complex and two narratives illustrate this. The first voice is that of the Knox household. Mr and Mrs Knox, 67 and 69 respectively, live in a house they bought through the 'Right to Buy' in the mid Northumberland market town of Alnwick. While Country Life magazine (2002) stated it was the best place to live in the UK, Mr and Mrs Knox's home is on an estate where crime and antisocial behaviour are commonplace. Mrs Knox was a domestic at a large country house but lost her job through rheumatoid arthritis, which has left her largely housebound. Mr Knox was a lorry driver who was invalided out of his job 20 years earlier as a result of a traffic accident. Since then, their main source of income has been Mr Knox's disability living allowances, which he periodically had to fight to retain through tribunals. They have not retired into poverty; rather, it has been a shaping characteristic of their lives: 
1 Mr Knox: 3 4 5 6 7 8 9 10 Mrs Knox:

'Health and a little bit more cash, so, because I would like to take [wife] to a show, something to get her out of the four walls. Well really, how do you put it, it's no good having your health if you've got nae money. Because there's things you want to do, and you can't afford to do 'em. And we've never had a holiday ... never had a holiday. I just hadn't got the cash. I have never been away with my wife. How long have we been married? Forty-seven years?'

'Forty-three years.'

2 One generation ahead, Miss Duncan, a 91-year-old former headmistress 13 who never married, retired on a teacher's pension after more than 30 14 years' service. She lives in her own home in the city neighbourhood 15 where she has lived all her life. She has been progressively losing her 16 sight for 20 years and more recently has experienced some hearing loss. 17 With no family and increasing frailty she is dependent on care workers 18 three times daily for personal care for which she pays the full charges: 19

\section{Miss Duncan:}

'I tell you what older people resent, those who have a lot to pay for their care - I pay £150 per week, which is a lot of money and its only because I worked and have a pension from teaching and people who had the same opportunities didn't take them or who spent every penny they had, get the same care and pay nothing or practically nothing. I hear that all the time from older people.'

29 While their working lives and incomes in retirement were markedly 30 different, in later life both the retired professional woman and the 31 retired manual workers' household have limited choices, the first 32 through being penalised for her higher income by means testing and 33 the second by a lifetime of low income and no savings. These are not 34 stories of malnutrition or fuel poverty but of the monotony of daily 35 life unrelieved by little opportunity for change and choice.

36

37

38

39 In England in 2013 people in the top 20\% for household income 40 made a quarter more trips than those in the lowest $20 \%$, and travelled 41 twice as far. The key factor in personal mobility is access to a car (DfT, 42 2014:10). Finances are not the only reason that people do not drive; 
many factors linked with later life can limit access to personal transport. Recognition of the restrictions placed on older people by lower income, the increasing likelihood of driving cessation (Ziegler and Schwanen, 2011) and evidence that poor mobility limits both physical activity and social interaction has been addressed by the introduction of free local bus travel (Green et al, 2014). In the fieldwork, concerns about getting out and about by public transport were among the first issues raised by those in affluent and disadvantaged neighbourhoods. The contribution to bus services by local authorities has been subject to cuts, as Age UK (2014a) notes, with $46 \%$ of local authorities cutting spending on their supported bus services in 2013/14 and 36\% cutting or removing services. In a Newcastle neighbourhood characterised by multiple deprivation, the bus service that used to operate through their estate and into the city centre had been withdrawn, leaving people with services accessed from the adjacent arterial road:

\title{
Mrs Clark:
}

\begin{abstract}
'Why should people here have to get taxis - people who've had hip operations? You see some people are in agony - why should they have to get a taxi to get their pension. Who cares about old people - not the ward councillors! I wrote a two page letter saying that LinkUp should concentrate on areas like ours that have no service. Nothing has happened and I heard nothing at all from them.' (Disadvantaged neighbourhood focus group)
\end{abstract}

Judged on frequency, the services that run down the side of the estate are good but for large numbers of older people, 400 metres away or further, the journey to the bus stop was impossible. Pre-paid taxis were required for some focus group respondents to travel to a venue 250 metres from their home. The impact on mobility of life limiting illness is more marked in disadvantaged areas (Public Health England, 2014; ONS, 2014), but does not form part of the calculation made by transport planners or bus operators. As older people have commented, the offer of community transport is inadequate and taxis were a largely unaffordable luxury.

Mobility seen as exercise, as engaging with opportunities for social exchange, for exercising choice in shopping for daily needs, for its role in reflecting back an identity of a person with independent movement was the most important material concern for older people shared across the income range. This reflects the views of a local older people's discussion group that commented on government measures of material 
1 deprivation: 'People with finances can still be materially deprived e.g. 2 lack of bus services/provision for elderly people and dangerous roads/ 3 busy roads unable to cross safely' (Newcastle Initiative on Changing Age, 2013: 9). Understanding the lack of material resources and mobility limitations demands a more nuanced approach. Beyond these there were other poverties to be endured.

\section{Poverty of relationships}

10 The research found older people who were well networked and 11 engaged in pleasurable activities and exchanges. These included 12 younger participants and two of the three oldest old, whose lives were 13 enviably enriched through their faith community that had established 14 social activities and support mechanisms. Age alone was not a predictor 15 of loneliness or isolation but those without immediate family close by 16 were more vulnerable as were those with limiting disabilities or with 17 little or no English. For those like Mrs Shah who had to contend with 18 all three, life had become a struggle to alleviate boredom and lonely 19 days. Her social life is dependent on a local voluntary sector group 20 that struggles to find the necessary funding: 21

\section{Mrs Shah:} 23 24 25 26 27 28 29 30 31 32 33 34 35 36 37 38 39 40 41 42
'Loneliness is a big problem. Now my husband is dead and my children are gone I feel isolated. Poor health stops me feeling independent. I need more company and more social contact. Loneliness is a very depressing thing. We live for coming out - even if only for a few minutes. There is only so much TV you can watch, only so many books that you want to read. If we could meet more often we would be less isolated. We meet together every Tuesday and if a letter comes we have to remember to bring it with us so someone can tell us what it says. It is easy to forget. Most days there is nothing to kill the time.' (Asian women's focus group)

Being connected, feeling valued, having friends, not just care workers employed to assist with daily living, was the most important issue after physical health - though it should be noted in that regard that waves of research now demonstrate that loneliness is as serious a health risk as obesity and smoking, with both physical and cognitive impacts (Age UK, 2012). Maintaining social connectivity and building new 
personal convoys of support is not only a challenge for individuals but for society as a whole.

\section{Violence}

Violence toward particular ethnic groups, older people, gay men and women, sexual violence against women in general and the chilling cosiness of 'domestic violence' are some of the most potent ways in which people categorised as 'other' are objectified. Statistics demonstrate that older people are least likely to be victims of any crime, much less violent crime, nevertheless surveys including evidence from Newcastle (NCC, 2013) suggest that people over 65 are least likely to report feeling safe in their locality after dark, leading to careful planning of both mode and time of travel. From the fieldwork, $\mathrm{Mr}$ and Mrs Knox continually have to manage intimidation, criminal and antisocial behaviour from their neighbours, including children:

Mr Knox:

'I mean they'll come round, they'll spit on you, they get nails and scratch your car, and if you say anything like, "Look, I'm going to see your mother." "What do you think she's going to do, like?" They vary from what, 11, from about 11,12, downward. They'll come down here on an old bike with flat tires, that'll go out. That bike will be thrown out into grass down by the road and they'll go out and pinch somebody's new one. Owt they see, they pinch. There's a family called $[\mathrm{F}]$, broke into my birdhouse and pulled some of the heads off my birds.'

Violence takes a number of forms and behind closed doors older people may be subject to physical, psychological, sexual and financial abuse that, because it happens in private, is difficult to capture or quantify (Fitzgerald, 2004); but public exposure - as in the 2013 jailing of a care worker in Newcastle for abusing dementia patients - can serve to open up the issues (Kennedy, 2013). Recent shocking reports revealed widespread neglect of older people in NHS hospital wards that left vulnerable elders in wet beds suffering from malnutrition and dehydration (Abraham, 2011). The Equality and Human Rights Commission (2014) has highlighted evidence of neglect and cruelty in care homes while the Resolution Foundation (2014) has revealed the impact of minimum (or even lower) wages on the quality of home care services procured by local authorities, which underlines the low 
1 value that is placed on older people's wellbeing. This can be viewed 2 as the lack of compassion at the heart of the state's offer to vulnerable 3 adults, but it is also evidence of the impossible decisions that many 4 local authorities have to make in fulfilling their duty of care in times 5 of public austerity:

'My next door neighbour (private sheltered housing apartment block) is having big mental problems and they are doing wonderful jobs for her and at first they just came in to look at her. And in half an hour they have to do so much it is ridiculous, they cannot get her out of bed, she's very deaf, wash her, shower her, and give her her breakfast in half an hour. I've timed myself, I mean I just do what I want so I thought I'll try and rush myself, get out of bed, have a shower, have my breakfast, I can't do it in half an hour. Her flat is filthy now [sighs] they've now actually managed to get someone in to clean and do her shopping. She shouldn't be there but that's another worry but a home help used to be someone quite different, became your friend and people do need someone to have a cup of coffee with, not this rushing all the time because they have to get there poor souls and move on to the next one.' (Affluent neighbourhood focus group)

Beyond these experiences there was a current of incivility, frequently or resented passengers who took time to board the bus. Miss Duncan, as a professional woman, now dependent through being blind and 30 hard of hearing, was highly conscious of casual disrespect and battled 31 against what she perceived as a societal view that she was incompetent:

32

33 34 35 36 37 38

39 40 41 42

Miss Duncan: 'One of the worst things that happen to older people is being talked down to ... there's another thing if there is a dispute of any kind or any doubt about it, you are doubted straight away because you are old - your word is not taken because you are old and that hurts.'

And it is this 'othering' and invisibility that Young talks of as the paradoxical oppression of 'cultural imperialism', which is understood as 'to experience how the dominant meanings of society render the particular perspective of one's own group invisible at the same time 


\section{1}

as they stereotype one's group and mark it out as the Other' (1990: 58-59). In so far as the active third ager has come to dominate the discourse, it is clear that those who have come to frailty and disability suffer from being seen as failed ageing people; it is also clear that those in the third age struggle to be seen as not frail, as not needing care as 'not other'. These struggles mirror the tension between those physically disabled people battling against assumptions that they are intellectually impaired while those with learning disabilities fight to be recognised and valued.

\section{Powerlessness}

Those who were dependent on needs assessments by professionals and were provided with services seen as appropriate to these needs were the voices of powerlessness in this study. Having concluded an interview with an older man in a care home, one of the authors saw him wheeled away and 'parked' with his back to a group of older women in chairs, where he was left without the possibility of conversation with any other person. These casual and unconscious displays of power were presumably commonplace. Beyond the care home, the gaps in the offer of the state made to those with no or insufficient command of the English language left older Asian women feeling helpless:

\section{Mrs Gerai:}

'I think our health is worse because we often miss hospital appointments. We get a letter and cannot read it. An interpreter has to be arranged to meet us at the hospital, sometimes they come to the wrong hospital or we go the wrong hospital. If we are at the wrong hospital we find it difficult to get to the right one. Sometimes the interpreter does not come at all. The interpreter cannot take us there; they can only meet us there. I need - we all need - an escort service. Ambulances need to be booked. Nothing is on our side.' (Asian women's focus group)

Those who received home care were vulnerable in areas where they risked exploitation through a restricted understanding of their needs:

Miss Duncan: Not being able to see I get very het up about my financial affairs. I think there should be someone to help those older people who don't have a family. You have no privacy because I have to ask the carers 
to read a letter for me and it might be very personal or something financial and I don't want everyone to know what I have.

And yet Miss Duncan is one of the fortunate in receiving any service. Statistics from Age UK (2014b) reveal the painful shortfall experienced by many frail and vulnerable older people who are unable to access either formal or family provided support. Some 870,000 people aged 65-89 who do not qualify for local authority support, cannot pay for 10 private care and have no family support, have to struggle as best they 11 can. This number includes four in five who need help taking their 12 medication (200,000 out of 240,000); over two thirds who find it hard 13 to eat on their own $(160,000$ out of 250,000$)$; a half who struggle 14 to wash/get in the bath $(500,000$ out of $1,010,000)$; over two fifths 15 who find it difficult to get dressed (590,000 out of 1,300,000); more 16 than 1 in 3 who find it difficult to go to the toilet $(120,000$ out of 17 350,000); and 1 in 3 who find it hard to get out of bed on their own 18 (190,000 out of 570,000). The consequences for those lacking support 19 were indicated by a small scale qualitative study with people deemed 20 ineligible for social care by their social services department, which 21 identified a range of outcomes including examples of 'self reliance' that 22 could be seen as dangerous and potentially injurious to self-esteem 23 (Tanner, 2001). Newcastle City is one of the local authorities that has 24 restricted its offer of domiciliary support to those older people whose 25 needs are categorised as 'critical' (DoH and DCLG, 2014). Even in 26 this tightly targeted offer, it does not consistently offer a service that 27 pays attention to need and dignity.

28

29

30

\section{Confronting oppression}

31 The mapping of older people's experiences onto the architecture of 32 oppression is merely a first, though not inconsiderable step. The next 33 important step is for older people to begin to make the connections 34 between the transformations in minority civil rights they have 35 witnessed taking place in their adult lives and their own struggles as 36 older people to live with dignity, be treated with parity and to have 37 their own voices respectfully heard. A number of the baby boomer 38 generation has already shown itself immune to the internalised sense 39 of lesser entitlement of previous cohorts and are able to speak out 40 against the cultural and institutional bias against people in higher age 41 groups in the wider culture. The challenge is to move this into strategic 42 agenda for action. 


\section{1}

In Newcastle, older people came together in the late 1990s, first through the Better Government for Older People pilot scheme and then as the Elders Council of Newcastle, to provide a mechanism for enabling older people to have a stronger voice and to provide a platform for older people to make a contribution to city life. The concept of uncovering older voices of experience to highlight areas for work is a core value of the organisation as is working in partnership with policy makers and providers in the public, private and third private sectors to develop solutions. That older people can be heard and have access to key actors is an important step to changing the way policy actors do business and conceptualise older people's needs. However, the impact was only ever to be piecemeal without greater political commitment, which happened in 2011 when Newcastle City Council became a signatory to the Dublin declaration signalling its intention to become an age-friendly city, where everyone can flourish regardless of their life stage. The vision of Newcastle age-friendly city is to transform the city in ways that take account of the changing age profile when planning for the future, so that ageing is embedded in all policies speaking to other key agendas; that takes an asset based approach to the role of older people in the city and takes the indignity and dependency out of the way some people experience old age. Action goes ahead on multiple fronts, enlarging the conversation so more actors are made aware of what the changing nature of age might mean for them. Social justice arguments need to be reframed as good business strategies so that increased life expectancy is seen as an economic good, not only because older people are consumers but because they may stimulate opportunities for innovation. In the housing arena, it is about challenging the industry to explore the full spectrum of older people whose aspirations include new forms of housing and possibly new ways of living. In the cityscape, the Royal Institute of British Architects (RIBA, 2013) have questioned whether our traditional high streets, our notions of learning and living spaces meet the challenge of an ageing society. This is a tough challenge given that post industrial Newcastle has refashioned itself as a party city, based on the high alcohol consumption of younger people, where other groups, both older and younger, may feel uncomfortably out of place. How can the city address the tensions that arise from the impact of alcohol tourism on both social life and urban fabric?

In the face of increasing public sector cuts and service models based on crisis responses, there is a recognition that upstream investment is needed in neighbourhoods so that people can be supported to age in place. Creative practice with a locally based arts group that 
1 works collaboratively on socially engaged performance has helped 2 unlock stories of local resilience and community assets in two typical 3 city neighbourhoods. A key skill is determining impactful ways of 4 confronting professionals with older people's lived realities. Social 5 media, film making, dramatised narratives are more powerful than 6 reports in alerting key actors in the local authority and third sector to 7 how they may best deploy funds. That older people can develop greater 8 resilience through their own actions is encouraged through small funds 9 that facilitate the development of activities to address social isolation. 10 Resilience is also promoted through increasing digital engagement, 11 which is becoming more important in enabling older people to live full 12 and independent lives, ranging from access to information; developing 13 and maintaining social networks; and, access to assistive technologies. 14 Digital inclusion may be a key to early intervention and action is being 15 taken by the local authority's commitment to increasing access to 16 superfast broadband and through increasing IT confidence via a digital 17 drop-in service provided jointly with Northumbria University students. 18 The question, of course is, does recognition - the increasing volume 19 of older people's voices; their engagement in the local policy arena 20 - lead to transformation? In the tough financial times, we need to 21 believe that a shared spatial imaginary will stimulate change and that 22 actions that challenge the oppression of our streets, transport systems, 23 care services and housing will lead to new ways of doing business.

24

\section{References}

26 Abraham, A. (2011) Care and compassion? Report of the NHS Ombudsman, 27 London: Parliamentary and Health Service Ombudsman.

28 Age UK (2012) Loneliness: The state we're in: Report for the Campaign to 29 End Loneliness, Abingdon: Age UK.

30 Age UK (2014a) Agenda for later life: Public Policy for Later Life, London: 31 Age UK.

32 Age UK (2014b) ' 870,000 older people do not receive crucial care 33 help', Latest News, 14 August.

34 Carers UK (2014) Caring \& Family Finances Inquiry UK Report, London: 35 Carers UK.

36 Clapham, D. (2014) 'Accommodation and support options for older 37 people in Britain and Sweden', In: European Network of Housing 38 Research conference, Edinburgh, 2-4 July.

39 Department for Transport (2014) National Travel Survey, England, 2013, 40 [pdf] Available at: 
https://www.gov.uk/government/uploads/system/uploads / attachment_data/file/342160/nts2013-01.pdf [Accessed January 2016].

Department of Health and Department of Communities and Local Government (2014) Adult social care in England: An overview, London: National Audit Office.

Department of Work and Pensions (2014) The Pensioners' incomes series, London: DWP.

Equality and Human Rights Commission (2014) Close to home: An inquiry into older people and human rights in home care, London: EHRC.

Fitzgerald, G. (2004) Hidden voices: Older people's experiences of abuse, London: Help the Aged.

Gilroy, R. (2009) Elder Count, unpublished report for Joseph Rowntree Foundation, copy available from the author r.c.gilroy@ncl.ac.uk.

Ginn, J. (2010) 'Unkindest cuts: the impact on older people', Radical Statistics, 103: 50-57.

Green, J., Jones, A. and Roberts, H. (2014) 'More than A to B: the role of free bus travel for the mobility and wellbeing of older citizens in London', Ageing and Society, 34(3): 472-94.

Higgs, P. and Jones, I.R. (2009) Medical sociology and old age: Towards a sociology of health in later life, Abingdon: Routledge.

Higgs, P., Leontowitsch, M., Stevenson, F. and Jones, I.R. (2009) 'Not just old and sick - the "will to health" in later life', Ageing and Society, 29(5): 687-707.

Hockey, J. Phillips, J. and Walford, N. (2013) 'Planning for an ageing society: voices from the planning profession', Planning Practice and Research, 28(5): 527-43.

Horwitz, W. (2014) Looking forward to later life, London: Community Links.

Institute of Fiscal Studies. (2013) Living standards, poverty and inequality in the UK, London: IFS.

Kennedy, B. (2013) 'Newcastle care home bully jailed for abusing frail dementia sufferers', Newcastle Chronicle, [online]. Available at: http:// www.chroniclelive.co.uk/news/north-east-news/newcastle-carehome-bully-jailed-6313861[Accessed January 2016].

Means, R. and Evans, S. (2014) 'Communities of place and communities of interest? An exploration of their changing role in later life', Ageing and Society, 32(8): 1300-18.

Newcastle City Council (2013) Know your Newcastle. [online] Available at: http://www.wellbeingforlife.org.uk/know-your-city [Accessed January 2016]. 
1 Newcastle Initiative on Changing Age (2013) The Pensioner Material Deprivation Indicator, Years Ahead Task Group report, Newcastle:

Newcastle University.

ONS (2014) Health inequality widest in older middle-aged census analysis shows. [online] Available at: http://www.ons.gov.uk [Accessed January 2016].

7 Public Health England (2014) Newcastle upon Tyne: Health profile 2014, 8 London: Public Health England.

9 Resolution Foundation (2014) Low pay Britain, London: Resolution 10 Foundation.

11 RIBA (2013) Silver linings: The active third age in the city, London: RIBA. 12 Rowe, J.W. and Kahn, J.L. (1997) 'Successful aging', Gerontologist, 13 37: 433-40.

14 Tanner, D. (2001). 'Sustaining the self in later life: supporting older 15 people in the community', Ageing and Society, 21: 255-78.

16 Walker, A. (2004) 'The ESRC growing older programme 1999-2004', 17 Ageing and Society, 24(5): 657-74.

18 World Health Organization (2007) Global age-friendly cities: A guide, 19 [pdf] Available at: http://www.who.int/ageing/publications/Global_ 20 age_friendly_cities_Guide_English.pdf [Accessed January 2016].

21 Young, I.M. (1990) Justice and the politics of difference, Pittsburgh, PA: 22 University of Pennsylvania Press.

23 Ziegler, F. and Schwanen, T. (2011) 'I like to go out to be energised 24 by different people: an exploratory analysis of mobility and wellbeing 25 in later life', Ageing and Society, 31(5): 758-81. 